07

\title{
Изменение строения поверхностного слоя гетерогенного твердого тела (гнейса) при сдвиге
}

\author{
(C) В.И. Веттегрень ${ }^{1}$, А.В. Пономарев ${ }^{2}$, K. Arora $^{3}$, Р.И. Мамалимов ${ }^{1}$, И.П. Щербаков ${ }^{1}$, А.В. Патонин ${ }^{4}$ \\ ${ }^{1}$ Физико-технический институт им. А.Ф. Иофрфе РАН, \\ Санкт-Петербург, Россия \\ ${ }^{2}$ Институт фоизики Земли им. О.Ю. Шмидта РАН, \\ Москва, Россия \\ ${ }^{3}$ CSIR National Geophysical Research Institute, \\ Hyderabad, India \\ ${ }^{4}$ Геофизическая обсерватория „Борок“ - филиал Института фризики Земли им. О.Ю. Шмидта РАН, \\ Борок, Россия \\ E-mail: Victor.Vettegren@mail.ioffe.ru
}

(Поступила в Редакцию 28 декабря 2016 г.)

Методами фотолюминесцентной и инфракрасной спектроскопии исследовано строение поверхностного слоя толщиной $\sim 1 \mu \mathrm{m}$, образовавшегося при разрушении горной породы - гнейса. Обнаружено, что в этом слое кристаллы полевых шпатов (плагиоклаза и микроклина) полностью разрушены и вместо них образовался монтмориллонит.

Работа выполнена при финансовой поддержке российско-индийского проекта PHФ-DST India: грант Российского научного фонда № 16-47-02003, грант Департамента науки и технологии Правительства Индии - INT/RUS/RSF/P-13.

DOI: 10.21883/FTT.2017.07.44595.462

\section{1. Введение}

При сдвиге хрупких гетерогенных твердых тел, таких как горные породы, часто образуются гладкие поверхности, получившие название зеркал скольжения. Их образование вызывает резкое (на порядок) уменьшение коэффициента трения породы и может служить причиной неустойчивости скольжения горных пород. Экспериментальные исследования строения природных зеркал скольжения на поверхности гетерогенных твердых тел - горных пород (песчаника ПВ 364, доломита и порфирита) - были начаты в работах [1-4]. Обнаружено, что они содержат нанокристаллы минералов, имеющих низкий коэффициент трения. Затем было проведено исследование поверхностного слоя толщиной $30 \mathrm{~nm}$, образовавшегося на поверхности пластинок из песчаника ПВ 364 после трения в условиях лаборатории [5]. Оказалось, что этот слой тоже состоит из нанокристаллов минерала с низким коэффициентом трения - монтмориллонита (ММТ). Настоящая работа продолжает цикл этих исследований. В ней изучен состав поверхностного слоя, образовавшегося при сдвиге гетерогенной горной породы - гнейса.

\section{2. Объект и методы исследования}

Кусок гнейса был извлечен из скважины в зоне неоднократного повторения землетрясений в районе КойнаВарна, Индия. Он содержал 35-45\% полевых шпатов (плагиоклаз и микроклин), 40-50\% кварца и 5-15\% пироксенов и слюд. Из куска был выпилен стержень диаметром $30 \mathrm{~mm}$, а из него отпилены 2 образца. Один имел длину $60 \mathrm{~mm}$ и не сдержал видимых глазом дефектов. Второй - содержал естественную трещину, которая образовалась в породе до изготовления стержня.

Для деформации образца построена камера высокого давления, представляющая собой толстостенный стакан внутрь которого помещается образец. Сверху камера закрывается подвижным поршнем, передающим усилие, создаваемое прессом, на образец. Отдельная насосная станция создает внутри камеры гидростатическое давление $30 \mathrm{MPa}$ путем закачки туда масла.

Камера помещалась в гидравлический двухкамерный пресс INOVA, имеющий систему сервоконтроля [6]. $\mathrm{C}$ помощью программы управления задавали временну́ю зависимость смещения положения поршня пресса.

Для исследований строения породы были использованы методы инфракрасной (IR) и фотолюминесцентной (PL) спектроскопии.

Чтобы получить спектры PL, построили лабораторную установку. В ней луч ультрафиолетового светодиода UVTOP280TO39HS (длина волны излучения - $285 \mathrm{~nm}$ ), падал на поверхность образца. Возникающее излучение кварцевым световодом направлялось в спектрометр AvaSpec-ULSi2048L-USB2 OEM. Диаметр луча светодиода, падающего на исследуемые поверхности торцов цилиндра и трещины, составлял $2 \mathrm{~mm}$, что на порядок меньше их размеров. Поэтому измерения методом PL проводились в трех разных местах, и полученные данные усредняли. На величину интенсивности полос в спектре 
PL сильно влияет рассеяние на шероховатой поверхности образца. Поэтому интенсивность луча лазера подбиралась такой, чтобы величина рассеянного излучения при всех измерениях была одинаковой.

Для записи инфракрасных (IR) спектров отражения использовали Фурье-спектрометр IR-21 „Рrestige“, снабженный приставкой для записи таких спектров SRM-8000A. Диаметр луча IR-излучения, падающего на исследуемую поверхность, составлял $20 \mathrm{~mm}$. Это означает, что методом IR-спектроскопии были получены сведения о содержании минералов в поверхностных слоях торцов цилиндра и трещин, усредненные по площади, близкой к их площадям.

Амплитуда электрического вектора света, падающего на поверхность поглощающего образца, затухает экспоненциально от поверхности вглубь. Эффективная толщина поверхностного слоя, о строении которого несет информацию спектр отражения, задана глубиной $h$, на которой амплитуда электрического вектора света уменьшается в $e \sim 2.7$ раз (e - основание натуральных логарифмов), а интенсивность света - в $e^{2} \sim 8$ раз. Она вычислена по формуле [7]

$$
h \approx \frac{1}{\pi v k_{e}},
$$

где $k_{e}-$ показатель поглощения, $v-$ частота IR-излучения.

Как уже упоминалось выше, поверхность образца сильно рассеивает свет. По этой причине, когда использовался метод PL-спектроскопии, оказалось невозможным оценить величину эффективной толщины поверхностного слоя.

Влияние рассеяния, когда применяли метод IR-спектроскопии, меньше. Это позволило для грубой оценки $h$ использовать значения, приведенные в $[1,4]$. В интересующих нас областях IR-спектра (800-1300 и $3680-3800 \mathrm{~cm}^{-1}$ ) она равна $\approx 1 \mu \mathrm{m}$.

\section{3. Результаты измерений и их обсуждение}

2.1. Данные механических испытаний. На рис. 1 показана временна́я зависимость давления при сжатии стержня вдоль его оси. Видно, что величина давления сначала растет, достигает $\sim 38.4 \mathrm{MPa}$, и затем резко падает. В этот момент появилась и начала расти трещина под углом $\sim 45-50^{\circ}$ к направлению сжимающей силы. Она разветвилась после того, как пересекла приблизительно половину диаметра образца (рис. 2).

Методами IR- и PL-спектроскопии исследовали строение поверхностных слоев торцов образца и трещины. Для сравнения исследовали также строение поверхностного слоя трещины, которая образовалась в породе до изготовления из нее стержня.

2.2. Результаты, полученные методом IR-cпектроскопии. Нa puc. 3 показан спектры

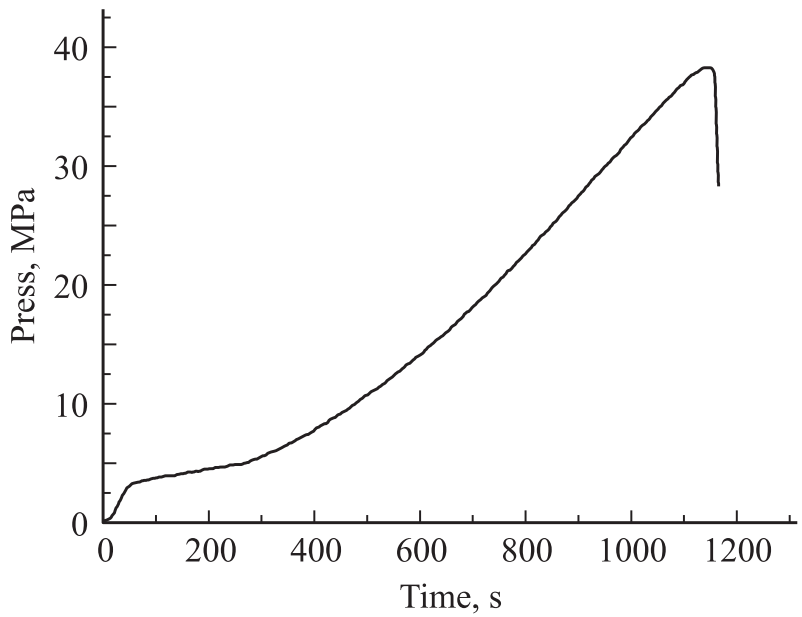

Рис. 1. Временна́я зависимость давления.

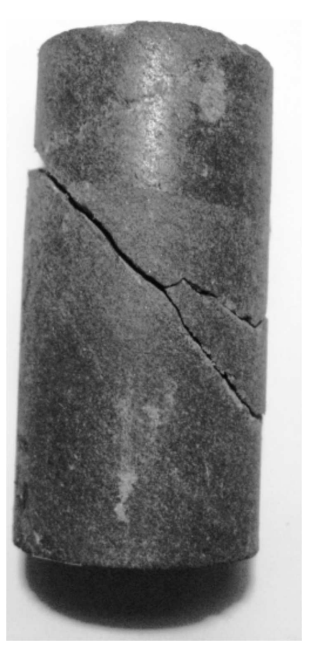

Рис. 2. Фотография исследованного образца после сдвига.

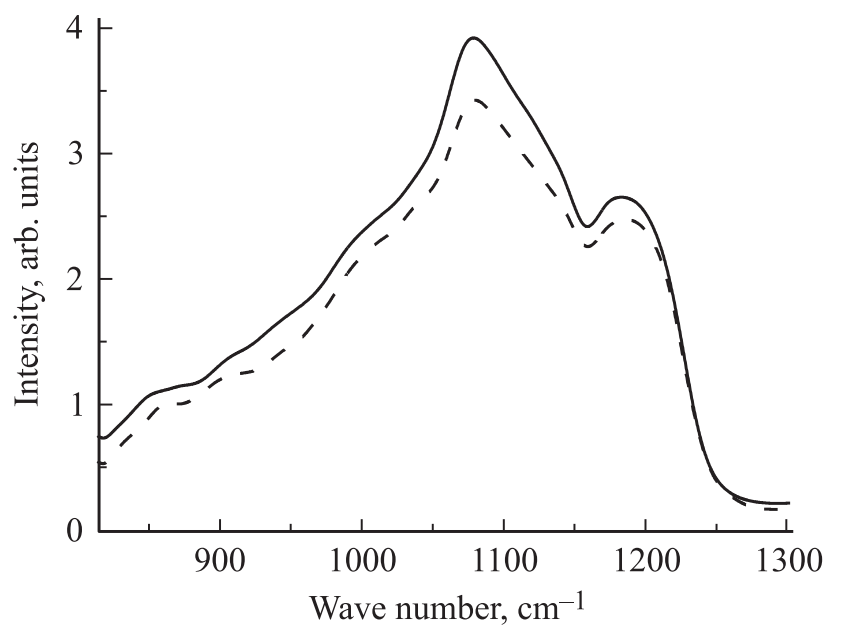

Рис. 3. Спектры противоположных торцов цилиндра в области $800-1300 \mathrm{~cm}^{-1}$. 


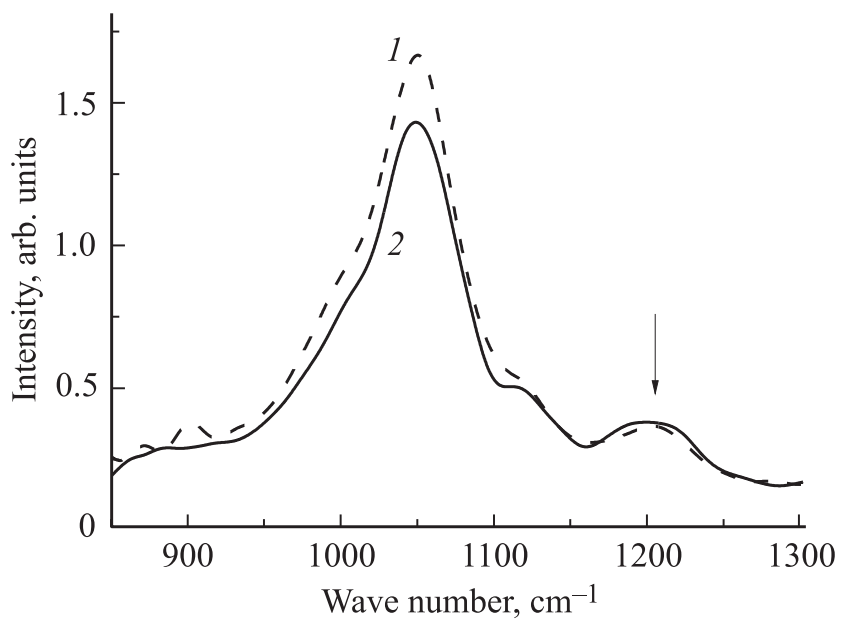

Pис. 4. Спектры отражения поверхностей трещин: $1-$ существовавшей до изготовления образца; 2 - образовавшейся в результате испытаний. Стрелкой показан максимум, соответствующий кварцу.

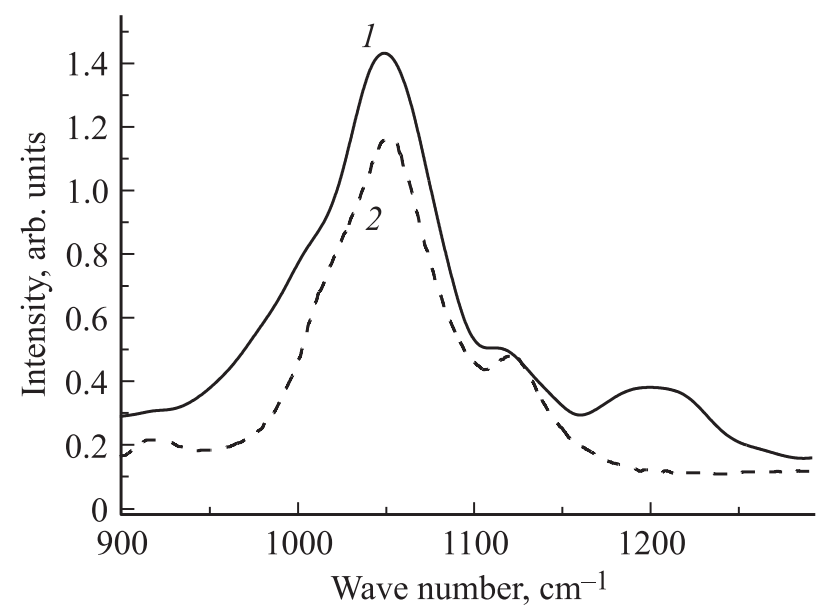

Рис. 5. Спектры отражения поверхности трещины (1) и MMT (2).

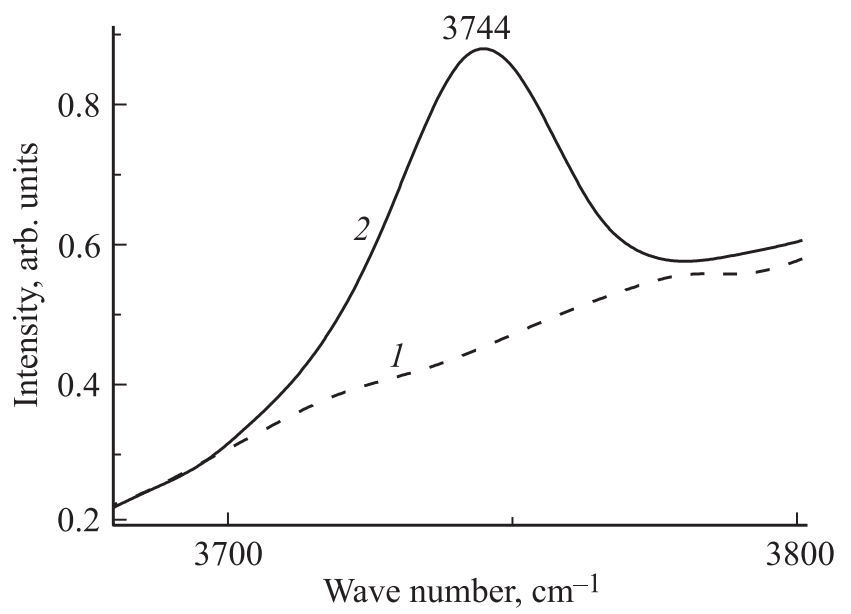

Рис. 6. Спектры отражения поверхностей торца цилиндра (1) и трещины (2) в области $3680-3800 \mathrm{~cm}^{-1}$.
IR-отражения противоположных торцов цилиндра в области $800-1300 \mathrm{~cm}^{-1}$. Из рисунка следует, что спектры торцов одинаковы. Это значит, что содержание минералов в поверхностных слоях толщиной $1 \mu \mathrm{m}$ обоих торцов цилиндра одинаково.

Анализ спектров показал, что они представляют собой результат наложения спектров кварца $[8,9]$ и полевых шпатов (плагиоклаза и микроклина $[10,11]$.

На рис. 4 приведены IR-спектры отражения поверхностей двух трещин: образовавшейся при разрушении образца в лаборатории и существовавшей в породе ранее - до его изготовления. Видно, что и они одинаковы, различается только интенсивность максимумов. Это показывает, что строение поверхностных слоев этих трещин одинаково.

В тоже время спектры отражения поверхностей трещин отличаются от спектров торцов цилиндра. А именно, в спектрах отражения поверхностей трещин появляются новые максимумы 1049 и $3744 \mathrm{~cm}^{-1}$ (рис. 5 и 6). Согласно [12] эти максимумы появляются в спектрах отражения монтмориллонита (ММТ) после его длительного размола. Это показывает, что в поверхностном слое трещин образуется ММТ, кристаллическая решетка которого содержит большое количество нарушений.

Кроме максимума $1049 \mathrm{~cm}^{-1}$ в спектрах отражения наблюдается максимум $1200 \mathrm{~cm}^{-1}$, приписанный колебаниям кристаллической решетки кварца (на рис. 4 он отмечен стрелкой). Его интенсивность в спектрах отражения поверхности цилиндра и трещины одинакова. Это показывает, что кристаллическая решетка кварца в поверхностных слоях цилиндра и трещины практически не нарушена.

В тоже время максимум $1077 \mathrm{~cm}^{-1}$, соответствующий полевым шпатам [10,11], в спектрах отражения поверхности трещины практически не заметен (рис. 5). Это показывает, что в поверхностном слое трещины полевые шпаты полностью замещаются на ММТ.

Вероятно, появление ММТ вызвано механохимическими реакциями. Действительно, известно, что под действием механических напряжений химические связи в кристаллических решетках полевых шпатов и кварца разрываются [13-17]. После разрыва связей образуются весьма активные свободные радикалы $\equiv \mathrm{S}-\mathrm{O}^{-}$и $\equiv \mathrm{Si}^{2+}$, которые вступают в химические реакции друг с другом, с молекулами воды и атомами алюминия, калия, натрия, входящими в состав полевых шпатов. Это ведет к образованию новых химических соединений и, вероятно, MMT.

Известно, что кристаллы горных пород содержат большое количество дефектов - ионов, примесных атомов и т. п. [18]. Интересно было выяснить — отличается ли концентрация дефектов в поверхностных слоях трещин и торца цилиндра? Чтобы ответить на этот вопрос была применена PL-спектроскопия.

2.3. Результаты, полученные методом PL-спектроскопии. На рис. 7 приведены спектры PL-поверхностных слоев торца цилиндра и тре- 


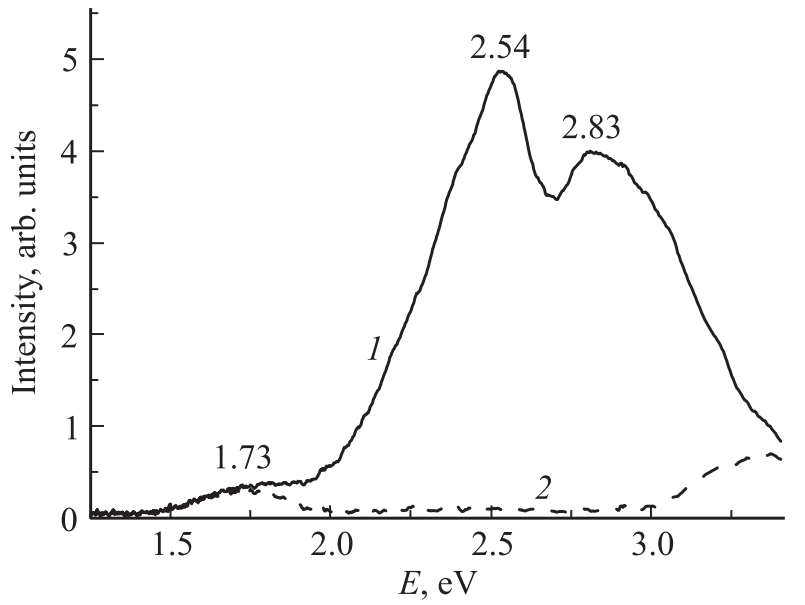

Pис. 7. Спектры PL-поверхностей цилиндра (1) и трещины (2).

щины. Они представляют собой результат наложения полос $1.73,2.54$ и $2.83 \mathrm{eV}$, приписанных дефектам кристаллической решетки кварца и полевых шпатов $[18,19]$. Полоса $1.73 \mathrm{eV}$ соответствует ионам $\mathrm{Fe}^{3+}$ в кварце. Полоса $2.54 \mathrm{eV}$ приписана центрам $\mathrm{O}^{-}-\mathrm{Si} \ldots M^{+}$, где $M^{+}$— ионы $\mathrm{Li}^{+}, \mathrm{Na}^{+}$или $\mathrm{H}^{+}$, а $2.83 \mathrm{eV}$ самозахваченным экситонам в полевых шпатах [19].

Видно, что концентрация центров $\mathrm{O}^{-}-\mathrm{Si} \ldots M^{+}$и самозахваченных экситонов в поверхностном слое трещины уменьшается практически до нуля. Этот эффект вызван разрушением кристаллической решетки полевых шпатов.

\section{4. Выводы}

1. Поверхностный слой торцов исследуемого образца толщиной $\sim 1 \mu \mathrm{m}$ содержит кристаллы кварца и полевых шпатов.

2. В поверхностном слое трещины такой же толщины полевые шпаты замещаются на МMT.

\section{Список литературы}

[1] Г.А. Соболев, С.М. Киреенкова, Ю.А. Морозов, А.И. Смульская, В.И. Веттегрень, В.Б. Кулик, Р.И. Мамалимов. Физика Земли 9-10, 17 (2012).

[2] Г.А. Соболев, В.И. Веттегрень, В.В. Ружич, Л.А. Иванова, Р.И. Мамалимов, И.П. Щербаков. Вулканология и сейсмология 3, 3 (2015).

[3] Г.А. Соболев, В.И. Веттегрень, В.В. Ружич, С.М. Киреенкова, А.И. Смульская, Р.И. Мамалимов, В.Б. Кулик. Геофиз. исследования 17, 4, 5 (2015).

[4] Г.А. Соболев, В.И. Веттегрень, С.М. Киреенкова, В.Б. Кулик, Р.И. Мамалимов, Ю.А. Морозов, А.И. Смульская, И.П. Щербаков. Нанокристаллы в горных породах. ГЕОС, М. (2016). 102 c.
[5] В.И. Веттегрень, А.В. Пономарев, Г.А. Соболев, И.П. Щербаков, Р.И. Мамалимов, В.Б. Кулик, А.В. Патонин. ФТТ 59, 589 (2017).

[6] А.В. Патонин, А.В. Пономарев, В.Б. Смирнов. Сейсмические приборы 49, 1, 19 (2013).

[7] M. Born, E. Wolf. Principles of optics. 2nd ed. Pergamon press, Oxford (1964). $856 \mathrm{p}$.

[8] W.G. Spitzer, D.A. Kleinman. Phys. Rev. 121, 1324 (1961).

[9] J. Etchepare, M. Merian, P.J. Kaplan. Chem. Phys. 60, 1873 (1974).

[10] E. Theodosoglou, A. Koroneos, T. Soldatos, T. Zorba, K.M. Paraskevopoulos. Bulletin of the Geological Society of Greece. Proc. 12th Int. Congress. Patras. M. (2010). XLIII, 2752.

[11] Zhou Lingdi, Guo Jiugao, Yang Nianhua, Li Liyun. Sci. China D 40, 2, 159 (1997). Kieffer S.W. Rev. Geophys. Space Phys. 17, 20 (1979).

[12] M.A. Karakassides, D. Gournis, D. Petridis. Clay Minerals 34, 429 (1999).

[13] G.N. Chapman, A.J. Walton. J. Appl. Phys. 54, 5961 (1983).

[14] Р. Силинь, А.Н. Трухин. Точечные дефекты и элементарные возбуждения в кристаллическом и стеклообразном $\mathrm{SiO}_{2}$. Зинатне, Рига (1985). 244 с.

[15] А.Н. Стрелецкий, А.Б. Пакович, И.Ю. Бутягин. Изв. АН CCCP 50, 3, 477 (1986).

[16] Y. Kawaguchi. Jpn. J. Appl. Phys. 37, 1892 (1998).

[17] В.И. Веттегрень, А.Я. Башкарев, Р.И. Мамалимов, И.П. Щербаков. ФТТ 50, 29 (2008).

[18] J. Götze. Microsc. Microanal. 18, 1270 (2012).

[19] Б.С. Горобец, А.А. Рогожин. Спектры люминесценции минералов. Справочник. Изд-во ВИМС, М. 294 с. 